\title{
16. Olpoi Village Pottery Making Today
}

\author{
Yoko Nojima
}

Lapita marks the beginning of pottery traditions in Vanuatu history. ${ }^{1}$ At the opposite end of this chronological sequence are the two pottery traditions known on the western coast of Santo: namely, Wusi in the southwest and Olpoi in the northwest (Figure 16.1). ${ }^{2}$ The well-known Wusi pottery certainly highlights the contemporary Santo pottery culture. In contrast, pottery production stopped almost half a century ago in the northwest, even though people still retain the knowledge of pottery manufacturing. This paper focuses on this latter case, the current situation of the pottery-making tradition among the people of Olpoi Village, based on my field experience in Northwest Santo in 2000-2001.

I first visited the village of Olpoi briefly in 1998, and returned for a year in 2000-2001 to conduct a dissertation research. Although pottery making was not the primary focus of my research, the place of pottery in the cooking system was one of my research questions. My visit was timely because Olpoi villagers had produced about a dozen pots just prior to my arrival in August 2000. They once again made some pots in 2001, and I was able to observe and record the process. This paper thus aims to update the research of Olpoi pottery technology to the beginning of the twenty-first century. By doing so, the place of pottery among the people of Olpoi today, and the impact of interaction with researchers in conceptualising their own understanding of the pottery are reconsidered.

\section{Pespia, Olpoi Village and pottery in Northwest Santo}

The place where pottery was once in production in Northwest Santo was reported as Pespia (Speiser 1996 [1923]). Today, Pespia is known as the name of a river running south of the Olpoi Village, and Pespia as a place name refers to a number of old settlements that were located upstream of this river. Pespia River remains the major source of their livelihood, supplying extensive riverine

\footnotetext{
1 My deepest gratitude goes to the people of Olpoi Village who accommodated me during my research. In particular I am grateful to chief Tavue and olfala Pala for all the support they provided. Alti Ezekiel and Helen Mark, fieldworkers of the Vanuatu Kaljoral Senta (VKS) in Northwest Santo also assisted me during my research. I would also like to thank J.-C. Galipaud for introducing me to the region in 1997, and Elizabeth Pascal for sharing the interest through personal communications regarding Olpoi pottery and Northwest Santo.

2 An area from Wusi to the north is generally known as 'West Coast Santo', while further north from Penaoru to Hokua in the western side of Cape Cumberland, is usually called 'Northwest Santo'.
} 
food resources and water for irrigated taro gardens and other daily purposes. Pespia Village might have been once located approximately eight kilometres up into the mountain (Mackenzie 1995), but current villagers do not know the exact location of this old village. Instead, they generally explain that there were many small family hamlets along the river, and that people used to relocate their settlements from time to time. There are no villages or settlements along the Pespia; however, the area is owned by the people of Olpoi Village, who are the descendents of Pespia potters.

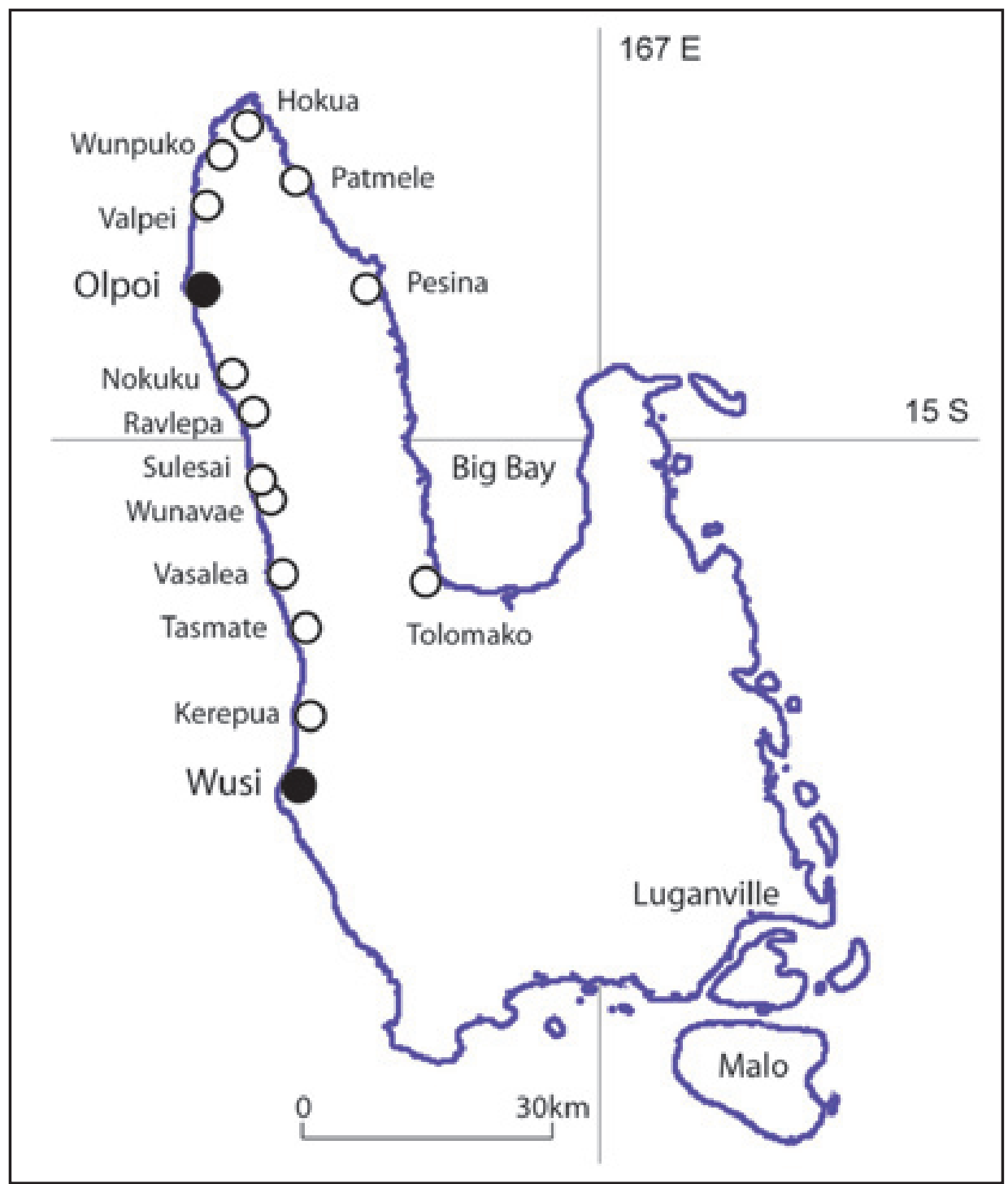

Figure 16.1. Map of Espiritu Santo 
Olpoi is a Christian village formed after the establishment of the Presbyterian Mission in Nokuku in 1890. Olpoi was likely founded in the early 1920s as a new Christian settlement of about 40 people (Miller 1978: 324). This small settlement was gradually joined by the people who used to live upstream of Pespia River, and eventually became one of the major villages in the northwest. During World War Two, however, villagers returned to the interior to avoid the war. As a result, many of the elderly in the village were born, not in Olpoi, but in the inland territories. They are the people who possess the knowledge of pottery making and retain memories of using pots through their parents. Pottery was frequently used by people until relatively recently. Typically, elderly individuals are familiar with the taste of food cooked in clay pots, and often say, 'This is what my mother used for preparing food for me.'
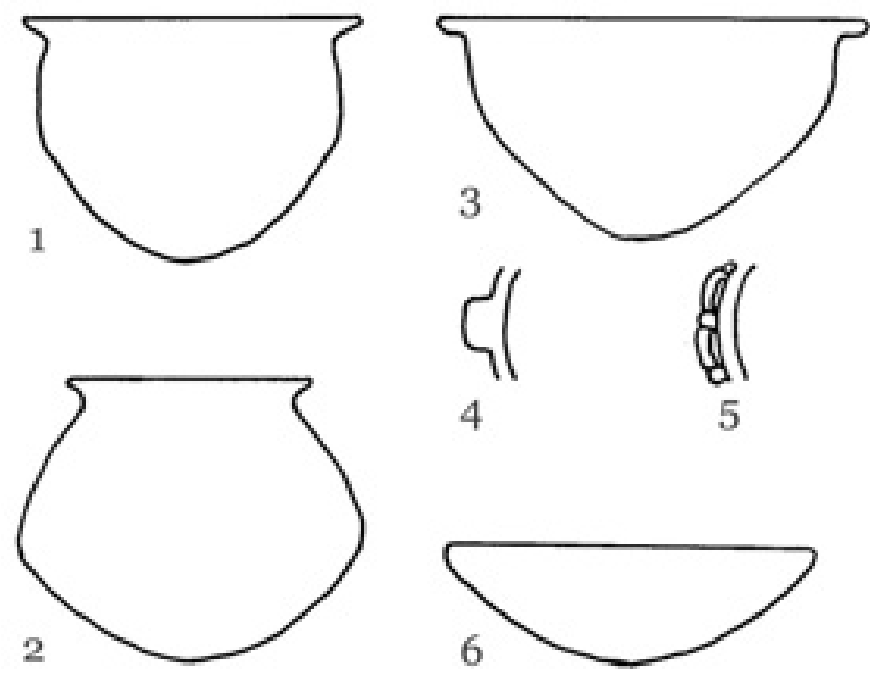

Figure 16.2. Schematic drawing of Olpoi-style pottery

(Yoko Nojima, c. 2000)

An old story in Olpoi recounts that pottery was brought about by a legendary man named Taval. According to the story, Taval went to his yam garden and found that a bamboo pole for supporting yam vines was swinging in the strong wind. The bamboo was tilted in all directions and created a round hole in the ground. Taval picked up this hole with curiosity, which became the shape of pottery. Variants of this story can be heard in the entire region of Northwest Santo including the Big Bay side. Interestingly, Taval is also the name of a source where people of Olpoi collect clay required for manufacturing pottery, although clay sources seem to be known in multiple locations in Northwest Santo. At 
Pesina on the Big Bay, for instance, there once was a known clay deposit. This source, however, is said to have been spoiled by a man contaminating the clay with sea water, and thus the pottery technology has been lost there.

Pottery in Northwest Santo is called welep, meaning 'a saucepan of ground'. There are four major forms in Olpoi-style pottery (Figure 16.2): 1. a pot with neck and an outcurving rim (wepran); 2. a pot similar to $1 .$, but with a narrow neck relative to the large diameter of the body (weaotot); 3. a tall, bowl-like pot with a straight rim (weanlan, wepatpat, or wepatmot depending on the decorative motifs on the rim); and 4. a shallow dish or bowl (ov). Among them, the first three are used for boiling, and are associated with the preparation of crops, cabbage and meat respectively, although the same pots are often used for any kind of food (Nojima 2010). Based on my observation, a particular fish called maj (a kind of freshwater goby) was the food most commonly cooked when pottery was used for cooking. This fish is frequently eaten in the western coast of Santo, usually boiled. When cooking this fish in pottery, sea water is used and boiled until all the water is evaporated (Figure 16.3). This cooking method, called waktos (wak=dry; tos=sea water), works better with a clay pot than with common metal pots, probably due to the different evaporation rate of water content. The preference towards the taste and texture of food cooked in pottery is recognised by the people. The major reason people do not use pottery for this cooking, they say, is a shorter cooking time and the easy handling of metal pots. Some informants in Northwest Santo mentioned that pottery was needed for cooking small portions of food, notably in relation to the grade system in which high-ranked individuals possessed their own fireplace to be separated from the others of lower status. This does make some sense because some pots found in old settlement sites in the bush are relatively small (with a maximum diameter of 15 centimetres or less), and some pottery employing the decorative motif of a boar's tusk is described as 'a pot for the chief' (Figure 16.4).

Pottery has been in intermittent production for at least half a century. Villagers remember that some pots were produced sometime in early $1980 s,{ }^{3}$ although this seems to have been a one-time event. The major explanations provided by the Olpoi people for not making pottery today are twofold. First, the people's shift from the interior to the coastal settlement distanced them from their clay sources so that it is now much harder to obtain materials for making pots. Second, it is often expressed that the current village environment is extremely dry, which is not good for making pottery. It seems most likely that the needs for clay pots have diminished to a great extent as the lifestyle of the people has been transformed as a result of Christianisation and increased Western influences. However, the availability, durability and expediency of metal pots rarely came up from the villagers as a reason for not making pottery; instead, they are the reason for not using pottery. 


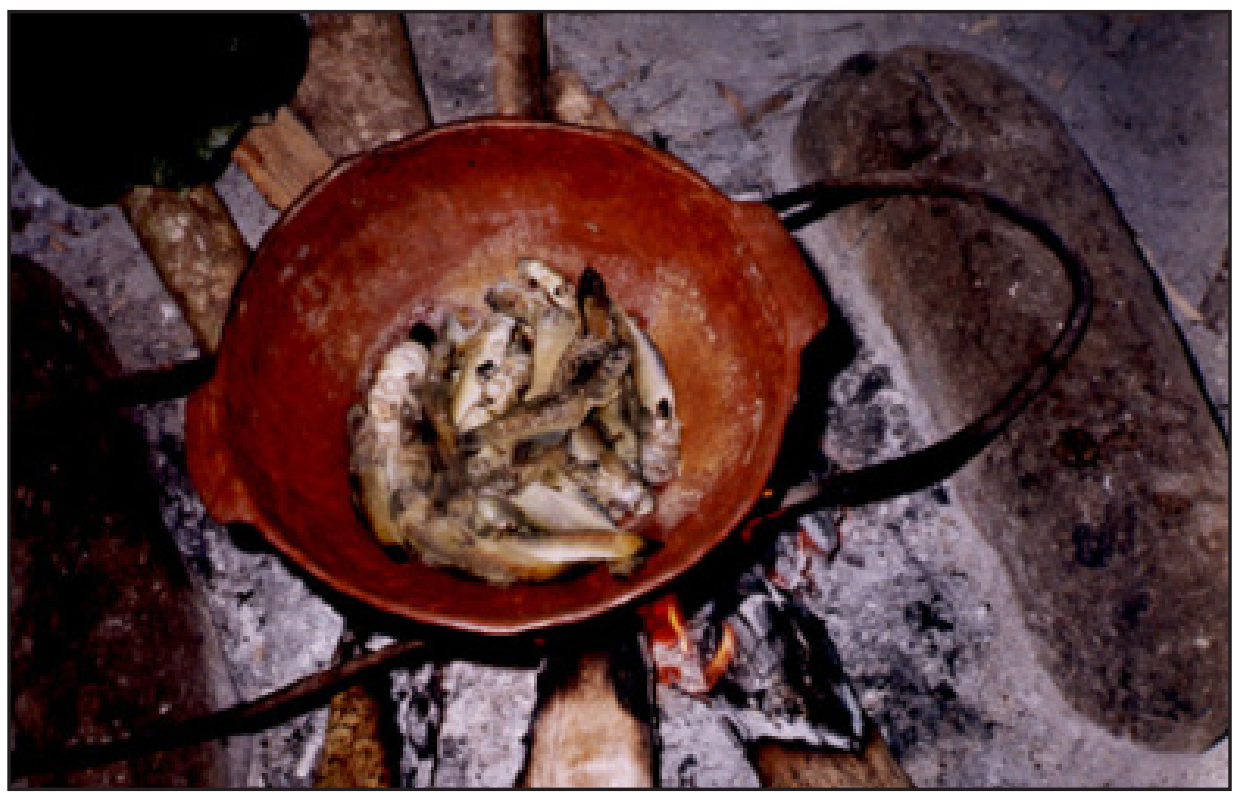

Figure 16.3. Maj Cooking

(Yoko Nojima, photographer, 2000)

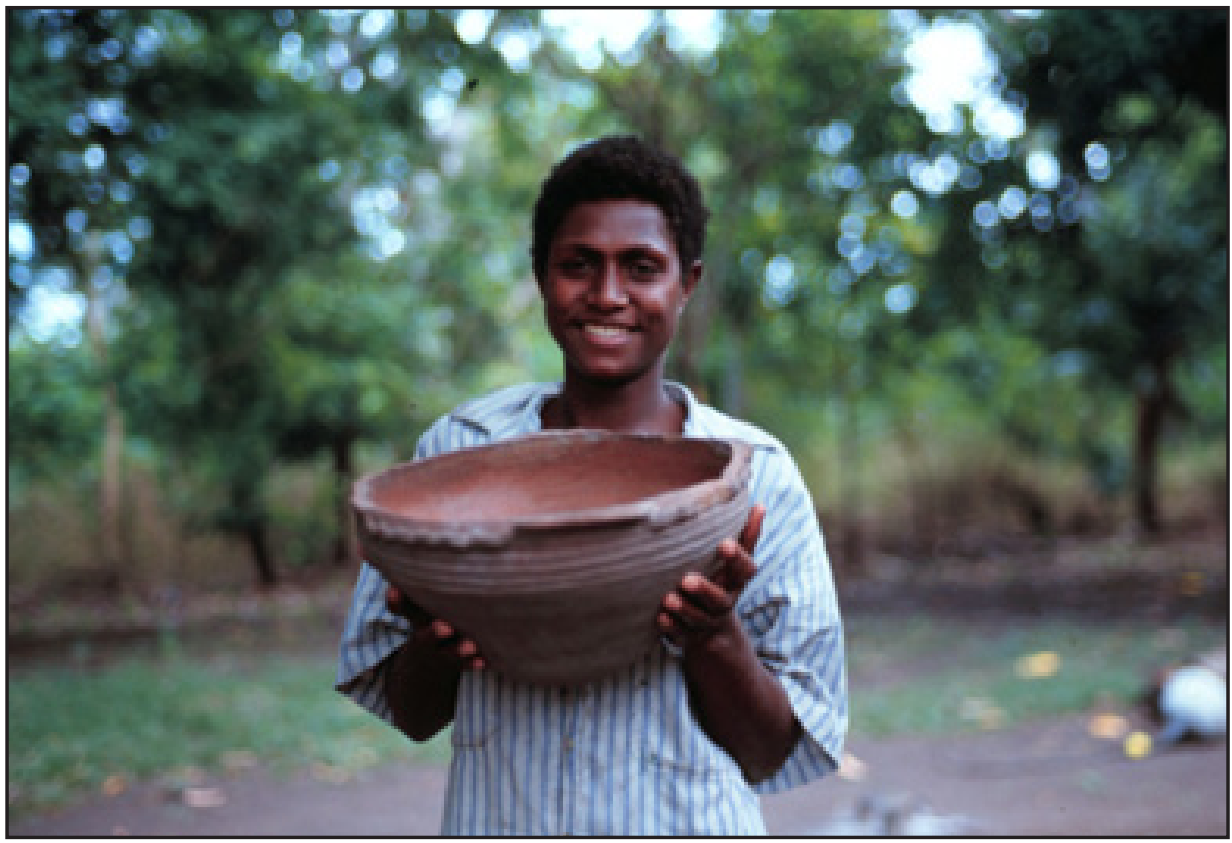

Figure 16.4. Olpoi Pottery

(Yoko Nojima, photographer, c. 1998) 


\section{Pottery making in 2001}

Ethnographic accounts in the early twentieth century attest that pottery was made only by females (Harrison 1936; Mackenzie 1995). Some elders in Northwest Santo also explained that pottery used to be made by females, while males helped them in the first step of clay preparation. Today in Olpoi, pottery is made by both men and women, although the majority of potters seems to be male. There is also an old man in a small settlement of Ravlepa to the south of Nokuku, who occasionally makes pots, because he used to observe his mother making Olpoi style pots.

The pottery making events in the years 2000 and 2001 were both organised by the Presbyterian Youth Group of the Olpoi Village, more or less as a project to learn their kastom of pottery making. Making pottery in 2001 was also a promise villagers made to me when I arrived in Olpoi in August 2000. However, when the season for pottery making came closer, the village youth became somewhat reluctant, saying that there was no time to go to the mountain to dig out clay and that they were too busy doing other work such as preparing copra. In the end, pottery making was carried out on a somewhat smaller scale than the previous year (pots were made by seven individuals, one piece each). Three of them were village elders who already had some experience making pots, and they helped others to learn how to make pots.

The basic process of pottery making remains the same as that recorded by F. Speiser, M.E. Shutler (1971), and more recently by Jean-Christophe Galipaud (1996). The following description summarises the pottery making carried out in 2001.

\section{Preparing clay and bamboo platform}

The clay is spread on a large flat board made of nakatambol wood (Dracontomelon vitiense). ${ }^{4}$ Before pounding a lump of clay, gravels contaminating the clay must be removed. Some water is added while pounding to attain ideal plasticity (Figure 16.5).

\section{Shaping pottery}

A bamboo cylinder is planted upright in front of the potter who is seated on the ground, on which clay, made into coils, is placed to form the body of the pots. Bamboo cylinders are occasionally rotated, serving as turntables for pottery making. After placing several layers of clay coils, it is smoothed and adjoined with wet fingers. Then the coiling process is repeated until the bottom half of the body of the pot is finely shaped (Figure 16.6). Then a flat disk of clay about

4 In Speiser's account (1996), however, the use of a stone table is noted. 
the size of a palm is placed inside to create the bottom of the pot. The upper body of the pot is then shaped in the same manner of coiling. When making a weanlan, one or two sets of handles (anlan=ear) are attached. Handles are created by applying 3-4 short clay strings of about the length of a finger. This style is considered easier to form because of its simple vessel shape and open profile, and is often chosen by young people in their pottery-making practice.

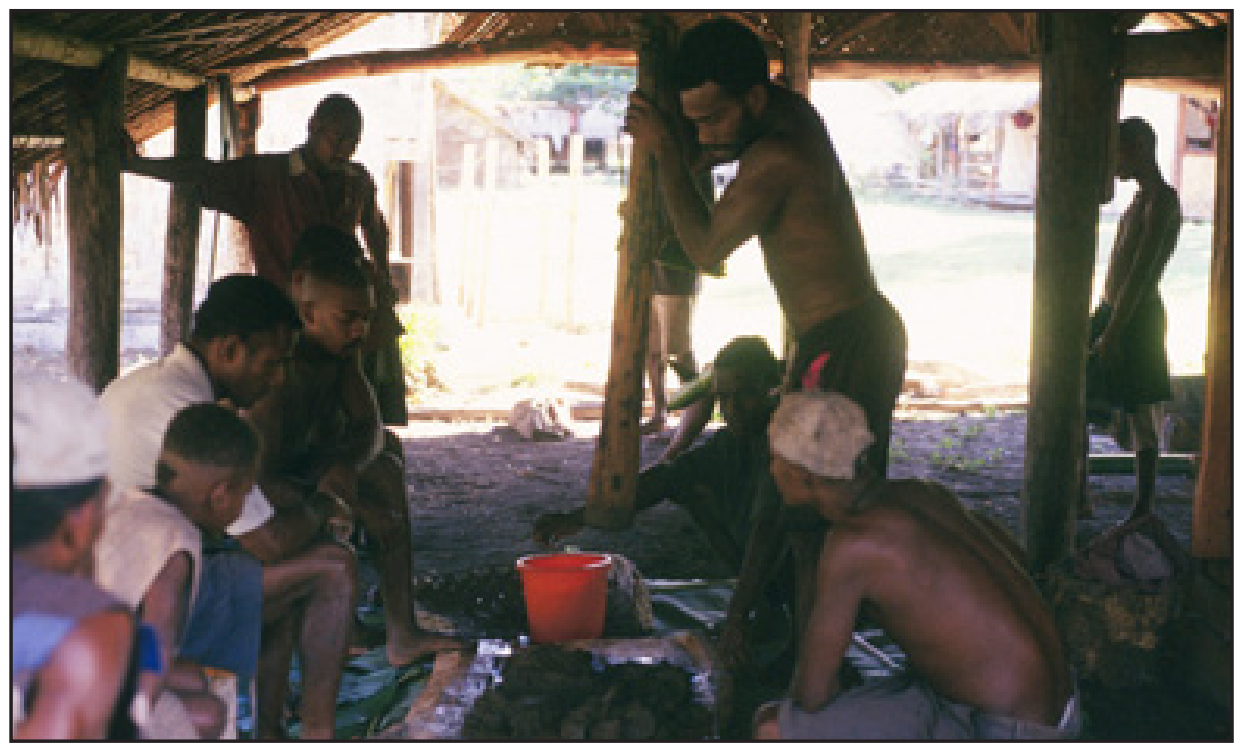

Figure 16.5. Preparing clay

(Yoko Nojima, photographer, 2001)

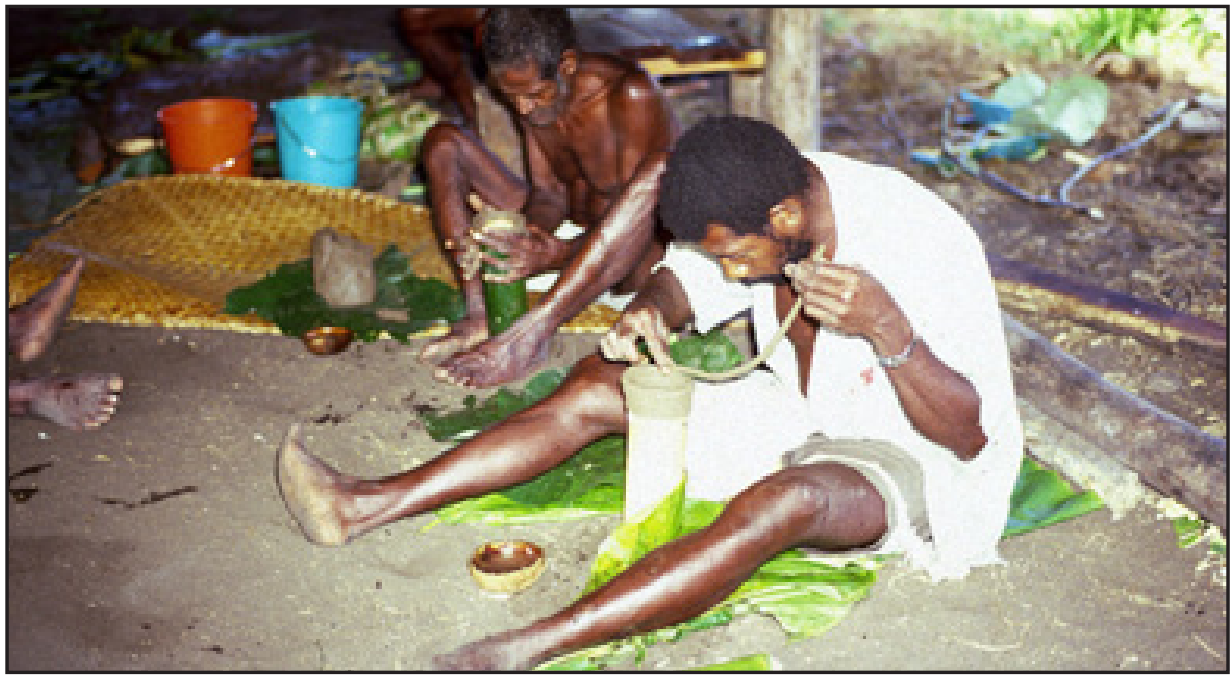

Figure 16.6. Coiling the clay

(Yoko Nojima, photographer, 2001) 


\section{Decoration}

It seems that the systematic decorative patterns or motifs are no longer in practice and that much knowledge regarding the decoration of pottery has vanished. While Shutler (1971) notes that Olpoi potters at the time of her visit possessed precise names for each decorative motif, I was unable to hear any explicit explanations. As a knowledge base for the decoration of pottery, the application of clay ropes and the use of fingernails, coconut midribs or citrus thorns for creating incisions are commonly shared (Figure 16.7). These are identical to the set of techniques recorded by Speiser. A motif employing a series of semi-circle clay ropes around the rim, known as patpat or 'a boar's tusk', is an exceptional case of well-known pottery design. ${ }^{5}$ When decorative patterns are applied to the surface, the pottery is finally removed from the bamboo base, and its exterior bottom surface is smoothed with fingers.

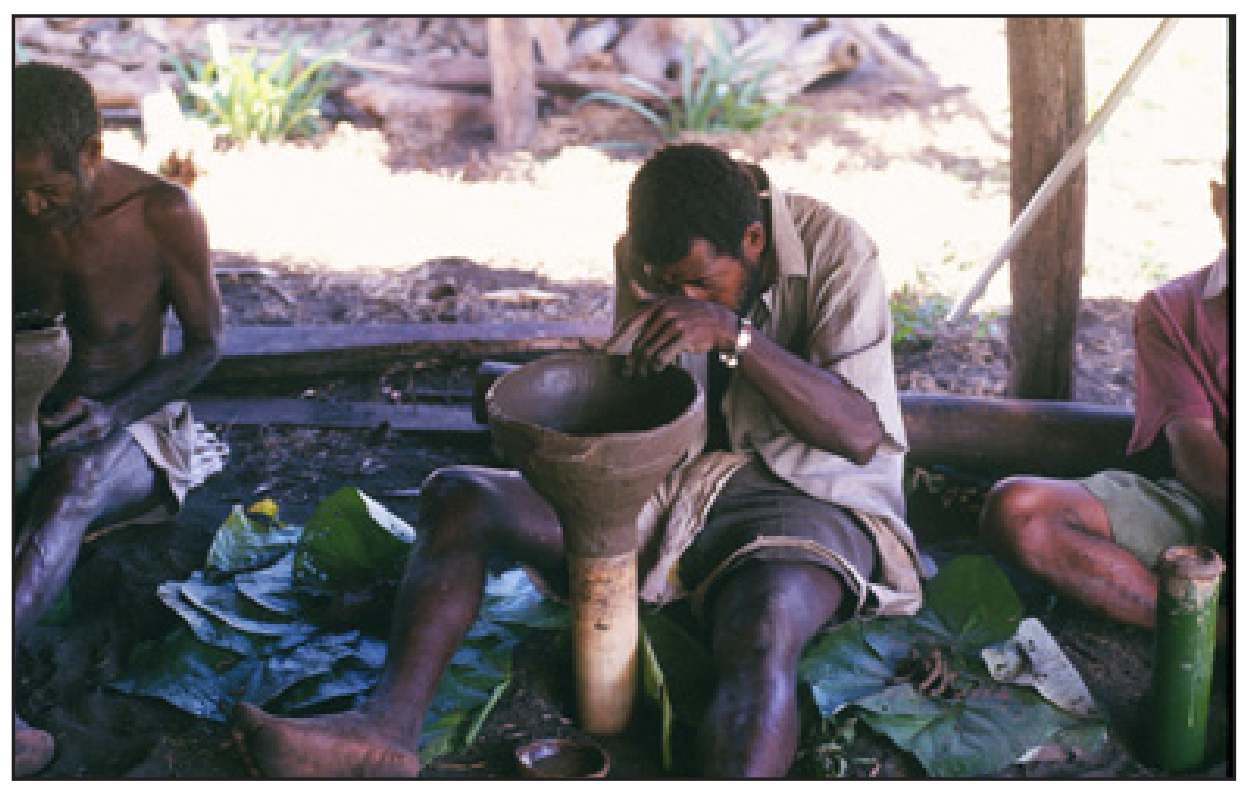

Figure 16.7. Decorating the pot

(Yoko Nojima, photographer, 2001)

\section{Applying red slip}

Red clay ( $\left.t a^{\prime} m e\right)$ is applied to the entire surface of the pot after a week of production, and pots are subsequently dried in a cool place for about a month. This process took longer than the case recorded by H. Mackenzie in

\footnotetext{
5 This pattern is also commonly applied for their large wooden plates for making nalot, an important dish in northern Vanuatu cuisine.
} 
which red paint is applied after two days and pots are dried for only five days (Mackenzie 1995: 69). Red clay is mixed with water inside a bamboo container, and softened fibre from a coconut husk made into an application brush is used for painting pots. When pots are dried and ready to be fired, extra red clay is scraped off and the scabrous surface of the pot is smoothed with large, diskshaped seeds of snakerope (Entada phaseoloides) (Figure 16.8). A sharp bamboo edge recorded by Mackenzie (1995) was not used in my observation.

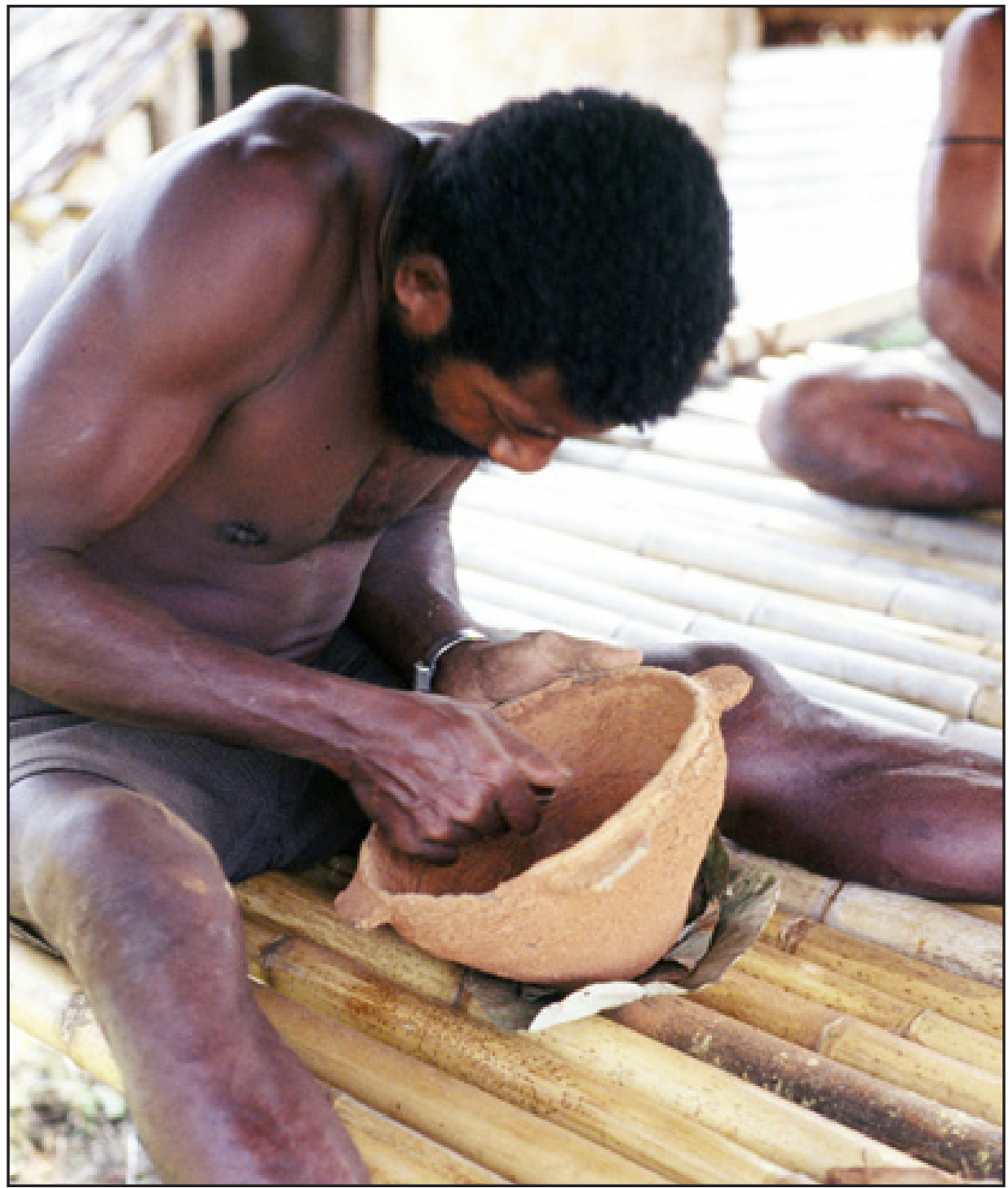

Figure 16.8. Smoothing the surface of the pot

(Yoko Nojima, photographer, 2001) 


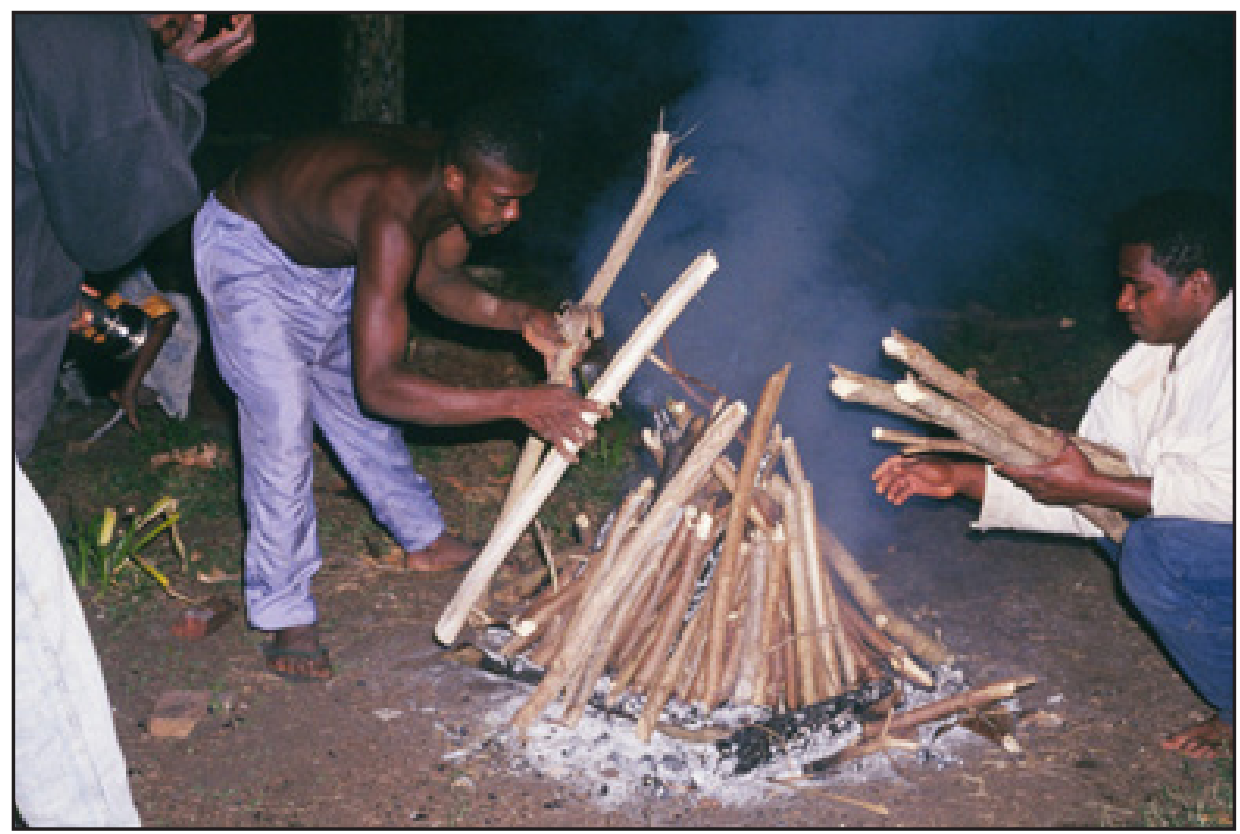

Figure 16.9. Placing firewood against the pots on the hearth platform

(Yoko Nojima, photographer, 2001)

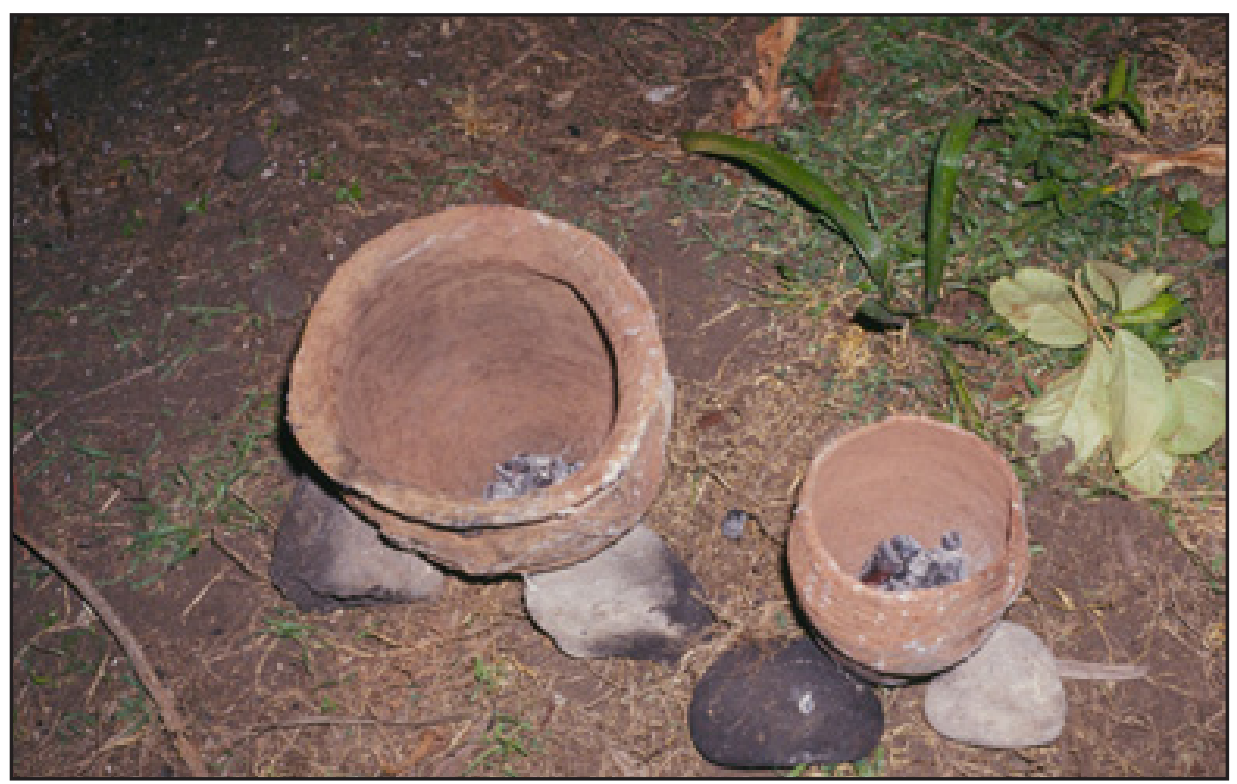

Figure 16.10. Fired pots are left outside until next morning

(Yoko Nojima, photographer, 2001) 


\section{Firing pots}

Firing was done at midnight (some villagers mentioned that it should be before dawn). Some stones are lined on the ground to create a hearth platform to place pots ready for firing. This hearth is first pre-heated by making a fire on top. The pot surface is rubbed with specific kastom leaves before firing. This magic ensures a successful firing without any cracks. Pots are then placed upside down on top of the pre-heated platform, and firewood is set against pots to cover them from the surroundings. Firewood for this purpose is supposed to be navenu (Macaranga), although people used burao (Hibiscus tiliaceus) at the time of my observation. Only two to three pieces of pottery were fired at once, but a larger platform could accommodate more pots. Firing takes only about 25 minutes. Although Shutler (1971: 82) writes that 'the pots are fired in a slow smouldering fire and left in the ashes until completely cold,' I observed firing done with a strong, flaming fire. Fired pots are immediately removed from the fireplace with wooden tongs. Fired pots are believed to be as strong as iron, so they could be picked around without any particular attention. These pots are then left outside until the next morning, with some charcoal pieces placed inside.

There are some taboos and magic (or what villagers also call kastom) associated with pottery making. It is said to be taboo for a potter to eat salt when he/ she is making a pot (Shutler 1971). This is generally taken literally and even consuming food containing salt is avoided. 'To eat salt' in fact is a connotation of sexual intercourse, and this is what has to be avoided before making pottery. The red colour symbolises Olpoi pottery as a product of strong kastom blessed by their ancestors. The red colour is a metaphor for the blood of ancestors. When villagers dig red clay, the names of the clan members who were deceased or killed are called, so that the blood of the dead will redden the soil. Digging sticks must be cut from a tree named $a^{\prime}$ a (Myristica fatua), whose sap is also red. When pots are fired, they have to be left outside so that spirits of the dead will come around to decorate them with their blood.

\section{Olpoi pottery in transition}

Archaeological evidence attests that pottery was once used almost everywhere in Vanuatu until about 2000BP in the south, 1200BP in the centre, and in Northern Vanuatu the pottery tradition lasted much longer and persisted in some regions to the ethnohistoric period (Bedford 2006, Bedford and Spriggs 2008). In the past 200 years, however, Santo was the only place in which pottery was produced and documented in ethnographic records. Geographical marginality and relative isolation of the west coast of Santo would have contributed greatly to the survival of pottery technology, without being heavily entangled in the wave of post-contact cultural transformations. Accordingly, this process made pottery an item more closely and distinctively associated with the people in this region. 
The production and use of pottery among the people of Santo has been recorded in major ethnohistoric and ethnographic accounts. The earliest remarks on Santo pottery come from the accounts related to the voyage of Pedro Fernandes de Quirós in 1606. Regarding the people of Big Bay, Quirós' journal says, 'the natives make from a black clay some very well-worked pots, large and small, as well as pots and pans and porringers in the shape of small boats' (Markham 1904: 269). Fray Martin de Munilla also writes, 'In this land was found something that has not been seen in any of the islands already discovered-namely many pots and pans of very good baked clay, and many wooden dishes and spoons' (Kelly 1966: 215). These records suggest the uniqueness and richness of pottery culture throughout the island of Santo. In the early seventeenth century, pottery could have also been in use on the other islands in northern Vanuatu (Bedford and Spriggs 2008: 110-12).

During the late nineteenth and early twentieth centuries, missionaries and ethnographers left some records on Pespia and its pottery (Mackenzie 1995; Rannie 1912). F.A. Campbell, a Presbyterian missionary who visited the area in the late nineteenth century, noted that pottery was made only in Santo (Campbell 1873). Steel (1880: 332) also left a brief remark on Santo pottery, saying 'they make a kind of unglazed pottery, which they use for culinary purposes; but they all say that their fathers made a far superior kind.' Acknowledging the existence of pottery in the region, it is noteworthy that a certain degree of technological limitation has already been mentioned.

Speiser was the first ethnographer to have left an in-depth documentation of pottery making in Pespia and Wusi. He records that pottery was made only in these two villages at the time of his visit, indicating the pottery production was no longer ubiquitous in the western coast of Santo. He also writes, 'the quality of the pots has sadly deteriorated. The examples of the older production which are still to be seen are markedly superior to modern wares in general shape, in the thinness of their walls, and in the delicacy of the ornamentation' (1996: 231-2). About 25 years later, T.H. Harrison (1936) notes that a female he saw at Pespia was the last potter. These statements point out that there was considerable transformation in pottery production during the late nineteenth and early twentieth centuries, probably in association with increased western influence upon their lifestyle. The spread of western cooking ware might have reduced the demand for hand-made pottery, which would have also lessened its value in exchange. ${ }^{6}$ Epidemics induced through Western contact causing population decrease might also have had considerable impact in transmitting the knowledge of pottery technology. ${ }^{7}$

6 The network of exchange connecting the islands of Vanuatu itself would have undergone considerable change concurrent with the sociopolitical transformation triggered by Christianisation and Western colonisation.

7 For instance, there was an outbreak of influenza in 1926 (Miller 1978). 
It was also in the early twentieth century that Santo pottery became the focus of ethnographical and anthropological research as a part of Melanesian pottery traditions (MacLachlan 1939; Schurig 1930). Since the 1950s, as archaeological investigations in the Pacific progressed with the discovery of Lapita and other traditions such as incised and applied relief potteries (Gifford and Shutler 1956) and the long-term history of pottery traditions in Melanesia became evident, ethnographic Santo pottery became the subject of researches, particularly by archaeologists. Shutler, who visited Santo in 1967, recorded pottery making in Wusi and Olpoi (Shutler 1968; 1971). While Wusi pottery technology was also recorded by Guiart (1956) in the 1950s, Shutler's brief article (1971) is the only source from which we can learn about the state of Olpoi pottery making during this time. She notes for Olpoi pottery that 'an admiring audience surrounds the potter and especially good pots are treasured as pieces of art,' whereas Wusi pots were made in haste for sale (Shutler 1971: 82). This statement would indicate that pottery making was no longer a common practice at Olpoi, while at Wusi pots seem to have been produced in quantity. The time of Shutler's visit probably marks the demise of pottery production at Olpoi, at least on an annual basis.

More recently, in the 1990s, Galipaud in association with Vanuatu Cultural and Historic Site Survey (VCHSS) did extensive surveys on surface pottery collections in the west coast, and recorded pottery making by an old man in Ravlepa (Galipaud 1996). This Ravlepa potter occasionally makes pottery as his mother who was from Olpoi used to do it. The same could be said for an old man in Olpoi who is also well-known as a potter. He principally learned how to make pottery by watching his mother making pots, rather than being trained to be a potter. Pottery making for them is a means of remembering their kastom. Some other Olpoi villagers also try making pottery from time to time most likely for similar reasons: because pottery is their kastom and an object reflecting their memories of the past.

\section{Pottery, Olpoi people today, and us}

Two ethnographically-known pottery-making villages have followed contrasting paths in the last century. The Wusi pottery tradition, despite the danger of its demise when devastating epidemics in the early twentieth century killed almost the entire Wusi population (Baker 1929), has been inherited and revived by the inland population who migrated to the coast and founded a new Wusi village (Galipaud 1996). ${ }^{8}$ Pottery is produced annually by Wusi women and sold to tourists in Luganville and Port-Vila, rather than being used for cooking by the

8 The contemporary Wusi language is thus different from the original one. In 2000, there was only one person who spoke the original Wusi language. 
local people. In contrast, Olpoi pottery gradually shifted to decline as its practical value in food preparation and exchange became diminished. Nevertheless, up to the present day, throughout the entire west coast, Olpoi pots are regarded as excellent cooking vessels.

The quality of pottery manufactured today is not as refined as pieces from older times. This would point to the current state of pottery technology among the Olpoi people, in which considerable knowledge has been lost. Considering that the diminishing quality of pottery was recognised almost a century ago, it is notable that the knowledge somehow endured this period of critical transformation and survived up to this century. The reason behind this would be the people's attachment to their own kastom, culture and history, all of which are symbolically materialised in pottery. At the same time, the westerners' admiration of their pottery and occasional visits of researchers who were interested in their pottery would have influenced the local people's perception of pottery as an item representing their history.

It is noteworthy that pottery was made in 2000 and 2001. In 2000, Olpoi people did it principally on their own initiative, although brief visits of researchers such as Galipaud and myself in the late 1990s might have indirectly encouraged their decision making. Nonetheless, it seems that people are facing difficulties in deciding how they should handle the situation. A person in the village noted that pottery making is a very important kastom for them, but he doesn't know how keeping this tradition would benefit their lives. Due to the geographical isolation, people often face considerable economic difficulties. The income of the people comes almost entirely from copra and cacao plantations; the produce from both can be sold only when a cargo ship passes through the west coast of Santo, a few times a year. For the Olpoi people, improving their economic situation is the most critical issue. Such economic hardship in turn is limiting their appreciation of traditional knowledge and time spent for making pottery. After 2001, pottery making in Olpoi did not continue into the following years to fully revive the practice. However, there was an unsuccessful attempt in 2007, suggesting that at least some people still possess a will to make pottery. Also, there has been some news from Ravlepa where families of the deceased old man who used to make pots have started learning and producing pottery in the past few years (Pascal, personal communication). ${ }^{9}$

Archaeologists tend to view the contemporary pottery technology overlaid on a chronological timeline relating to the prehistoric pottery sequence, and as a clue to understanding the history of the Pacific people, rather than evaluating it within a contemporary sociocultural context. Similarly, local people themselves seem to regard pots as objects that embody their history. As long as it is regarded

9 The updated information regarding pottery making in Olpoi and Northwest Santo is credited to correspondence with a researcher, Elizabeth Pascal, who has been visiting this area since 2004. 
as something of the past and distanced from their contemporary lives, it will be difficult to keep pottery alive. What is critical is to establish a solid foundation where pottery could be embedded in the lives of people in Northwest Santo. Finding a commercial route would be a way to do this-like the Wusi people are doing. It would also be possible for pottery to be developed again for culinary purposes. In any case, pottery making could be effectively used as a means of learning about kastom, as some Olpoi youth tried about a decade ago. Whether this art of pottery making will be carried through to the next generation depends on the people's decision and efforts today. Encouragement and support from researchers and the Vanuatu Cultural Centre are certainly beneficial in this critical process, as evidenced by the success of revitalising the kastom mat production on Ambae through the Women's Culture Project and the active involvement of researcher L. Bolton (Bolton 1994, 2003).

\section{References}

Baker, John R., 1929. Man and Animals in the New Hebrides. London: Routledge Press.

Bedford, Stuart, 2006. Pieces of the Vanuatu Puzzle: Archaeology of the North, South and Centre. Terra Australis 23. Canberra: Pandanus Books, Research School of Pacific and Asian Studies, Australian National University.

Bedford, Stuart and Matthew Spriggs, 2008. Northern Vanuatu as a Pacific crossroads: the archaeology of discovery, interaction, and the emergence of the 'ethnographic present'. Asian Perspectives 47: 95-120.

Bolton, Lissant, 1994. Bifo yumi ting se samting nating: the Women's Culture Project at the Vanuatu Cultural Centre. In Culture, Kastom, Tradition: Developing Cultural Policy in Melanesia, ed. L. Lindstrom and G.W. White, 147-60. Suva: Institute of Pacific Studies, The University of the South Pacific.

Bolton, Lissant, 2003. Unfolding the Moon: Enacting Women's Kastom in Vanuatu. Honolulu: University of Hawai'i Press.

Campbell, F.A., 1873. A Year in the New Hebrides, Loyalty Islands, and New Caledonia. Geelong: G. Mercer.

Galipaud, Jean-Christophe, 1996. Le rouge et le noir: la poterie Mangaasi et le peuplement des îles de Melanésie. In Mémoire de Pierre, Mémoire d'Homme: tradition et archéologie en Océanie, ed. M.J.M. Julien, M. et C. Orliac, et al, 115-30. Paris: Publications de la Sorbonne.

Gifford, Edward W. and Richard Shutler, 1956. Archaeological Excavations in New Caledonia. Anthropological Records 18. Berkeley and Los Angeles: University of California. 
Working Together in Vanuatu

Guiart, Jean, 1956. Grands et Petits Hommes de la Montagne, Espiritu Santo (Nouvelles Hébrides). Nouméa: Institut français d'Océanie.

Harrison, T.H., 1936. Living in Espiritu Santo. Geographical Journal 88: 243-61.

Kelly, Celsus, 1966. La Austrialia del Espiritu Santo: The journal of Fray Martin de Munilla, O.F.M., and other documents relating to The voyage of Pedro Fernández de Quirós to the South Sea (1605-1606) and the Franciscan Missionary Plan (1617-1627). Cambridge: The Hakluyt Society.

Mackenzie, Helen, 1995. Mackenzie, Man of Mission: A Biography of James Noble Mackenzie. Melbourne: Hyland House.

MacLachlan, R.R.C., 1939. Native pottery of the New Hebrides. Journal of the Polynesian Society 48: 32-55.

Markham, Clements (trans and ed.), 1904. The Voyages of Pedro Fernandez de Quiros, 1595-1606 vol. 1. Nendeln/Liechtenstein. London: Hakluyt Society.

Miller, J. Graham, 1978. Live: A History of Church Planting in the New Hebrides to 1880. Sydney: Committees on Christian Education and Overseas Missions, General Assembly of the Presbyterian Church of Australia.

Nojima, Yoko, 2010. Pottery as cooking vessels: the persistence of pottery technology in the western coast of Espiritu Santo, Vanuatu. People and Culture in Oceania 26: 57-79.

Rannie, Douglas, 1912. My Adventures among South Sea Cannibals: An Account of the Experiences and Adventures of a Government Official among the Natives of Oceania. London: Seeley, Service \& Co. Limited.

Schurig, M., 1930. Die Südseetöpferei. Leipzig: Druckerei der Werkgemeinschaft.

Shutler, M.E., 1968. Pottery making at Wusi, New Hebrides. South Pacific Bulletin 18(4): 15-18.

Shutler, M.E., 1971. Pottery making in Espiritu Santo. Asian Perspectives 14: 81-3.

Speiser, Felix, 1996. Ethnology of Vanuatu: An Early Twentieth Century Study, trans. D.Q. Stephenson. Honolulu: University of Hawai'i Press (originally published 1923).

Steel, Robert, 1880. The New Hebrides and Christian Missions, with a Sketch of the Labour Traffic and Notes of a Cruise through the Group in the Mission Vessel. London: J. Nisbet and Co. 